\title{
$\mathrm{CO}_{2}$ 포집을 포함한 석탄 가스화 시스템에서 급냉 방법에 따른 비교 \\ 이중원 ${ }^{\dagger} \cdot$ 김의식 · 고경호 · 정재화 · 홍진표 \\ 한국전력공사 전력연구원 사업화기술개발실
}

\section{Comparison of Quench Methods in The Coal Gasification System with Carbon Capture}

\author{
JOONGWON LEE ${ }^{\dagger}$, UISIK KIM, KYUNGHO KO, JAEHWA CHUNG, JINPYO HONG \\ Technology Commercialization Office, KEPCO Research Institute, 65 Munji-Ro, Yuseong-Gu, Daejeon, 305-760, Korea
}

\begin{abstract}
The integrated gasification combined cycle (IGCC) system is well known for its high efficiency compared with that of other coal fueled power generation system. IGCC offers substantial advantages over pulverized coal combustion when carbon capture and storage (CCS) is required. Commercial plants employ different types of quenching system to meet the purpose of the system. Depending on that, the downstream units of IGCC can be modeled using different operating conditions and units. In case with $\mathrm{CO}_{2}$ separation and capture, the gasifier product must be converted to hydrogen-rich syngas using Water Gas Shift (WGS) reaction. In most WGS processes, the water gas shift reactor is the biggest and heaviest component because the reaction is relatively slow compared to the other reactions and is inhibited at higher temperatures by thermodynamics. In this study, tehchno-econimic assessments were found according to the quench types and operating conditions in the WGS system. These results can improve the efficiency and reduce the cost of coal gasification.
\end{abstract}

Key words : Coal gasification(석탄가스화), Water gas shift reaction(수성가스반응), Quench method(급냉 방법), ASPEN PLUS(아스펜 플러스)

\section{1. 서 론}

가스화 복합발전(IGCC: integrated gasification combined cycle)이란 석탄, 바이오매스 등의 에너지 원료를 고 온고압 조건에서 반응 당량 이하의 산소 $\left(\mathrm{O}_{2}\right)$ 나 수증 기 $\left(\mathrm{H}_{2} \mathrm{O}\right)$ 와의 반응을 이용하여 불완전 연소시킴으로 써 일산화탄소 $(\mathrm{CO})$ 와 수소 $\left(\mathrm{H}_{2}\right)$ 가 주성분인 합성가스 를 생산(가스화)하는 공정을 포함하며, 이때 생성된

${ }^{\dagger}$ Corresponding author : joongwonlee@kepco.co.kr [ 접수일 : 2012.4.4 수정일 : 2012.5.30 게재확정일 : 2012.6.22 ]
합성가스와 열로 가스터빈과 증기터빈을 함께 구동 (복합 발전)시키는 전기 생산 공정을 말한다. 이러한 가스화 복합발전은 높은 압력의 합성가스로부터 연 소 전에 이산화탄소 $\left(\mathrm{CO}_{2}\right)$ 를 분리하는 것이 대기압상 태에서 이산화탄소를 분리하는 일반 화력보다 유리 하다. 따라서 CCS(carbon capture and storage)와 연 계될 때 이산화탄소 포집에 있어 유리하다 ${ }^{1)}$.

NETL(national energy technology laboratory) 에서 제공하는 "Cost and Performance Baseline for Fossil Energy Plants"의 Volume 3a(low rank coal to electricity 


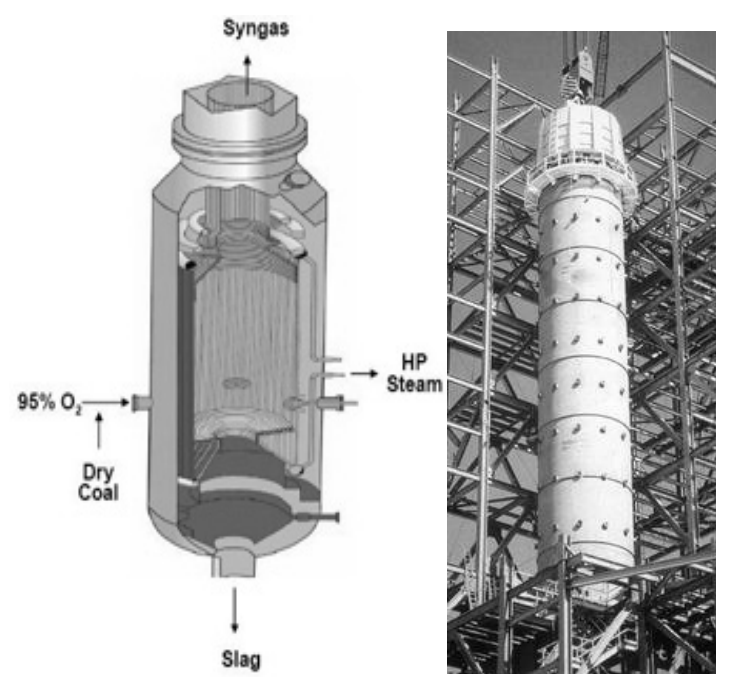

Fig. 1 Shell gasifier and radiant syngas cooler ${ }^{5)}$

: IGCC cases)를 참조하면 ${ }^{2}, \mathrm{CCS}$ 가 연계된 IGCC plant 의 total plant cost의 경우, $500 \mathrm{MW}$ 급 IGCC 건설을 위해 $\$ 2,600 / \mathrm{kW}$ 정도의 비용이 필요한 것으로 분석 되었다. 이 보고서의 경우 매년 개정되어 발표되고 있으며, 가스화복합발전 뿐만 아니라, 석탄화력발전, 천연가스 복합발전, $\mathrm{SNG}($ synthesis natural gas) 및 암 모니아 생산의 경우에 대하여 분석하여 결과를 제공 하고 있다. 본 연구에서는 2011년에 NETL에서 발표 한 자료를 기초로 하여 Shell과 Siemens 가스화기를 사용하는 경우에 대한 비교 연구를 수행하였다. NETL 의 연구는 ASPEN plus를 사용하여 모델링을 하였고 성능이나 공정의 제약 조건들은 기 발표된 자료를 기초로 하였다.

가스화기를 통해 생성된 합성가스의 경우, 여러 가지 불순물이 포함되어 있는데 최종적인 제품을 생 산하기 위해 정제 공정이 필요하다. 이러한 정제공정 을 수행함에 있어, 합성가스 냉각에 따른 현열의 효 과적인 이용이 가스화기 효율 향상 측면에서 중요한 부분을 차지하게 된다.

Shell 가스화기의 경우에는 radiant syngas cooler 를 적용하고 있으며, Siemens 가스화기의 경우에는 water quenching을 적용하고 있다. 이러한 합성가스 냉각 방법과 최종 목표 생산물(암모니아와 같은 화

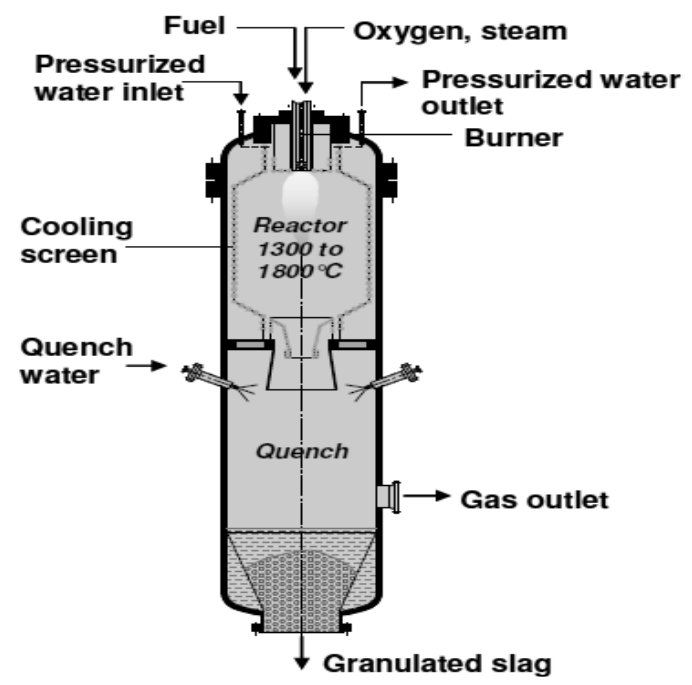

Fig. 2 Siemens gasifier ${ }^{6)}$

합물, 전기, $\mathrm{SNG}$ 등)에 따라 공정 후단의 운전조건과 장치 구성이 변경 된다. 특히, $\mathrm{CCS}$ 와 연계되는 것이 목표인 IGCC 가스화 공정에 있어서는 연소 전 포집 을 위해 WGS(water gas shift) 반응에 의해 수소 $\left(\mathrm{H}_{2}\right)$ 가 많은 조성으로 만드는 것이 필수적이다,4).

본 연구에서는 ASPEN plus를 이용한 기본 모델링 을 바탕으로 냉각 방법에 따른 차이점에 대해 비교, 분석하고자 한다.

\section{2. 이론적 배경}

\section{1 급냉(Quench)}

분류층 가스화기의 합성가스 급냉(quench)에 대하 여 radiant syngas cooler, water quench의 두 가지 경 우에 대해 비교해 보았다.

우선, radiant syngas cooler의 경우, Fig. 1과 같이 가스화기에서 생성된 고온의 합성가스가 열교환기를 통해 고온의 스팀을 생성한다. 이러한 시스템은 shell 가스화기 등에 적용되어 있다. Shell 가스화기의 경 우 냉각된 합성가스를 순환시킴으로써 가스화기 출 구의 온도를 약 $900^{\circ} \mathrm{C}$ 로 조절한 후 열교환기를 통해 열을 회수한다. 이러한 합성가스 냉각기의 경우에 현 


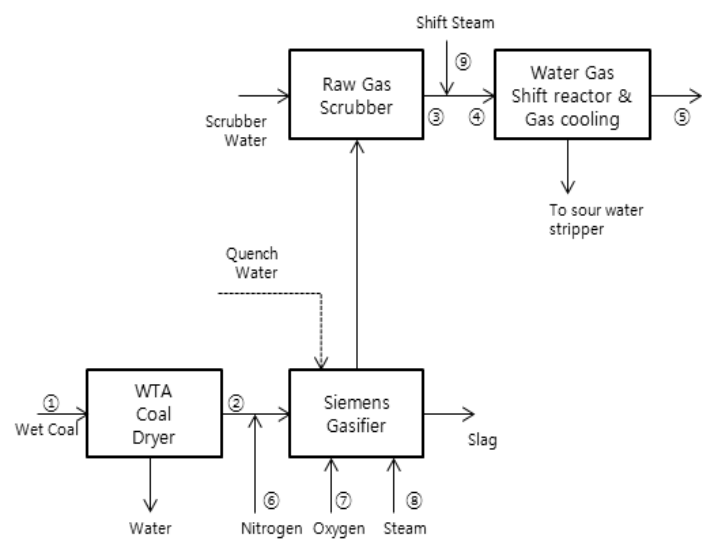

Fig. 3 Water quench block diagram

열을 회수하여 증기를 생산하는 장점이 있는 반면 초기 건설비 증가를 가져오는 주요 원인이 된다.

다음으로, water quench의 경우에는 siemens가스 화기 등에 적용되어 있다. 이는 Fig. 2 와 같이 생성된 합성가스가 가스화기 하부의 순환되는 물과 접촉하 여 합성가스의 온도를 낮추어 주는 시스템이다. 이러 한 경우에는 급냉수(quench water)를 순환하는데 있 어 복잡한 시스템이 사용되고 이러한 폐수를 처리하 기 위하여 flash vessel, 진공시스템, 순환 펌프 등이 사용된다. 사용되는 구조물의 재질의 경우에도 고온 고압 하에서 황(S)이나, 염소(Cl) 등으로 인해 선택에 어려움이 있다. 이러한 경우, 초기 건설비를 낮출 수 있는 장점이 있지만, 열회수 관점에서 불리하다.

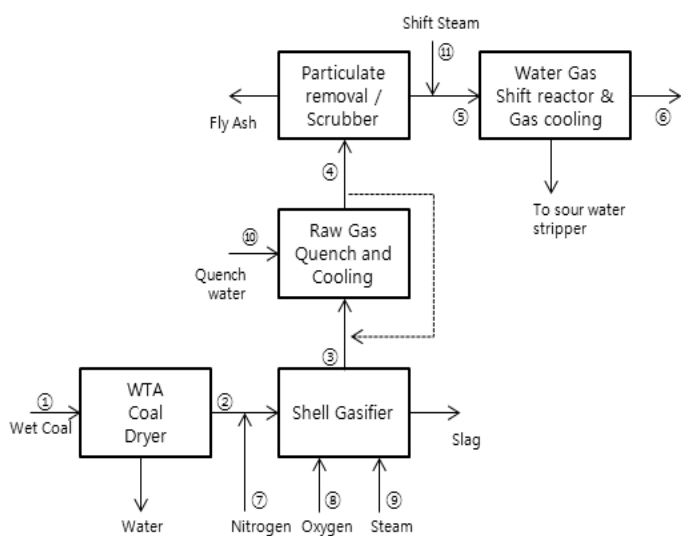

Fig. 4 Radiant syngas cooler block diagram

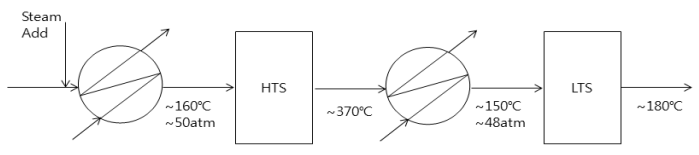

Fig. 5 WGS reactor $^{7)}$

이러한 두 가지 경우의 퀜칭 방법에 대하여, 공정 의 진행 과정을 원료 투입에서 수성가스 반응까지 살펴보면 다음의 Fig. 3과 Fig. 4와 같다 ${ }^{2}$.

\section{2 수성가스화 전환 반응(Water Gas Shift Reac- tion) ${ }^{7-10)}$}

합성가스는 가스화기에서 나온 이후, 연소 전 CCS 를 위해 수소가 많은 합성가스로 조성을 변화시킬 필요가 있다. 이를 위하여 수성가스화 전환 반응이 사용된다. 수성가스화 전환 반응의 경우 촉매를 이용 한 packed bed reactor(PBR)를 이용하여 반응이 이 루어진다. 수성가스화 전환 반응의 경우에 저온에서 반응이 이루어지지만, 반응속도 측면에 있어서는 고 온이 유리하므로 이러한 한계를 해결하여 위하여 일 반적으로 2개의 반응기를 이용하여 반응이 연속적 으로 이루어지도록 구성한다. 온도가 낮은 반응기 (low temperature shift reactor)와 온도가 높은 반응기 (high temperature shift reactor), 그리고 열교환기로 구성되어 진다. 촉매의 종류에 따라 차이가 있지만, 촉매의 수명과 활성(activity)을 유지하기 위해 유입 되는 물질의 온도 및 $\mathrm{H}_{2} \mathrm{O}: \mathrm{CO}$ 의 비율에 대한 제약 이 있다. 원하는 최종 물질이나 $\mathrm{CO}$ 의 높은 전환율 (conversion)을 얻기 위하여 이러한 온도 조건이나 $\mathrm{H}_{2} \mathrm{O}$ : $\mathrm{CO}$ 비율의 변화가 가능하다. 반응기로 투입되는 합 성가스의 온도 조절을 위해 반응기 전단에 열교환기 가 필요하고, 또한 수성가스화 전환반응은 발열반응 이므로, 이때 발생되는 열을 제어하기 위하여 두 개 의 반응기 사이 열교환기를 설치하여 발생되는 열을 제거 및 회수할 필요가 있다. 열교환기를 통해 회수 되는 열은 스팀을 발생시키기에 충분한 열이므로 첫 번째 반응기로 재순환하여 사용이 가능하다. 최종제 품에 따라 수성 가스화반응을 통해 $\mathrm{CO}$ 는 96 99\% 
Table 1 Feed analysis

\begin{tabular}{c|c|c}
\hline \hline Type & Components & wt (\%) \\
\hline \multirow{4}{*}{$\begin{array}{c}\text { Proximate } \\
\text { analysis }\end{array}$} & Moisture & 0.0 \\
\cline { 2 - 3 } & $\mathrm{FC}$ & 48.09 \\
\cline { 2 - 3 } & $\mathrm{VM}$ & 40.87 \\
\hline \multirow{4}{*}{$\begin{array}{c}\text { Ultimate } \\
\text { analysis }\end{array}$} & $\mathrm{ASH}$ & 11.04 \\
\cline { 2 - 3 } & $\mathrm{ASH}$ & 11.03 \\
\cline { 2 - 3 } & $\mathrm{C}$ & 67.45 \\
\cline { 2 - 3 } & $\mathrm{H}$ & 4.56 \\
\cline { 2 - 3 } & $\mathrm{N}$ & 0.96 \\
\cline { 2 - 3 } & $\mathrm{Cl}$ & 0.01 \\
\hline \multirow{4}{*}{ HHV } & $\mathrm{S}$ & 0.98 \\
\hline \multirow{2}{*}{ LHV } & $\mathrm{OJ} / \mathrm{kg}$ & 15.01 \\
\hline
\end{tabular}

까지 전환이 가능하다고 NETL보고서에서는 언급하 고 있달.

또한 수성가스화 전환 반응에 대한 운전조건은 Fig. 5에 나타나 있다.

\section{ASPEN Plus를 이용한 모사 프로그램}

본 연구에서는 석탄 투입과정부터 최종 수성가스 화 전환 반응까지 모사하였다. 가스화기에 관한 모사 는 관형 반응기(PFR(plug flow reactor))를 사용하였 다. PFR 이외에도 주로 많이 사용되는 반응기 모델
로 평형(equilibrium) 반응기의 경우, 화학양론 계산 에 의한 화학 및 상평형을 계산하는 경우에 사용하 고, 깁스(gibbs)반응기의 경우 gibbs 에너지 최소화에 의한 화학 및 상평형을 계산하는 경우 사용된다. 가 스화기 내에서 발생하는 water quench를 모사하기 위한 적합한 반응기 선정을 위하여 여러 종류 반응 기를 이용하여 모사하여 보았다. 수성가스화 전환 반 응 모사를 위해서는 촉매가 사용되는 관형 반응기 (plug flow reactor)를 통해 모사하였다.

\section{1 가스화기(Gasifier) $)^{1)}$}

가스화기의 모사는 열분해, 휘발분 연소, 가스화부 분으로 구성되어 있다. 전체적으로 모든 과정은 실질 적으로 가스화기에서 모두 일어나지만 가스화 모사 과정에 있어 각 반응들을 정확하게 모사하기 위하여 세분화 하여 모사하였다. 본 모델의 2010년 이중원 등에 의해 발표된 “석탄가스화 공정 모델링에 관한 연구"에 사용된 모델을 이용하여 탄의 성분을 변경 하여 모사하였다 ${ }^{1)}$.

공정 조건은 NETL 보고서의 운전변수 값을 그대 로 사용하였달. 본 연구에서 사용된 석탄의 물성은 Table 1과 같으며 공정도는 Fig. 6에 나타나 있다. 본 시뮬레이션에서 사용된 PFR의 크기는 길이 $3.25 \mathrm{~m}$, 직경 $1.5 \mathrm{~m}$ 를 사용하였고 이는 $\mathrm{ASPEN}$ 사에서 제공된

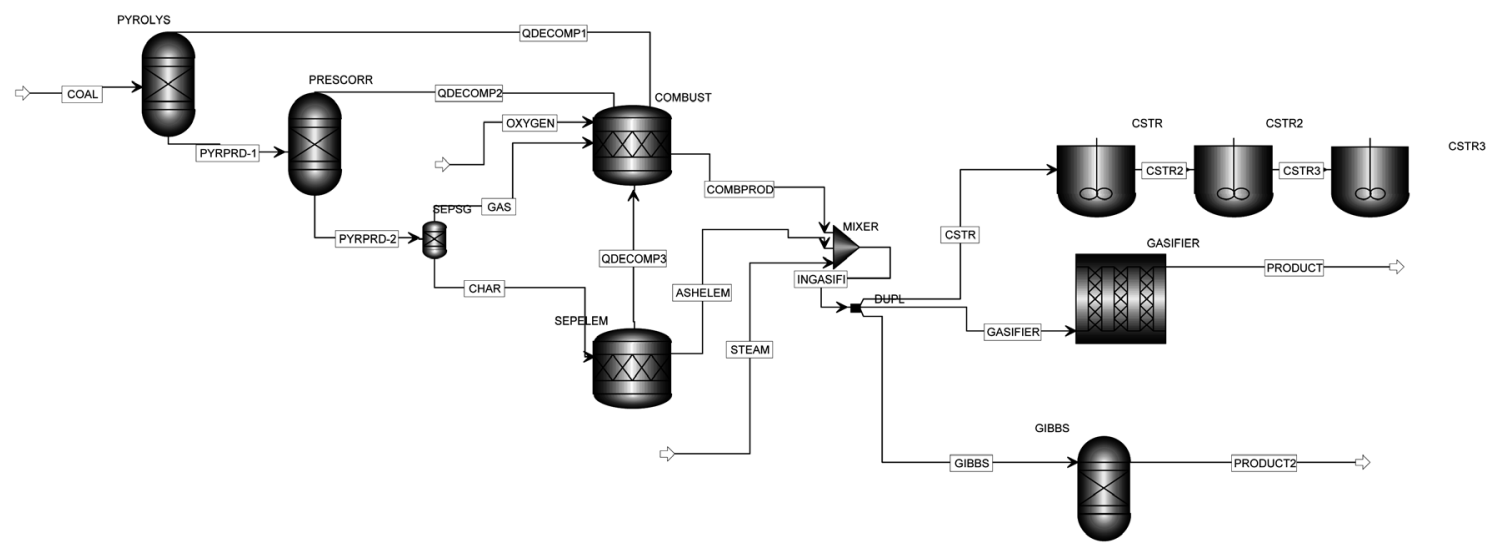

Fig. 6 ASPEN plus modeling ${ }^{1)}$ 


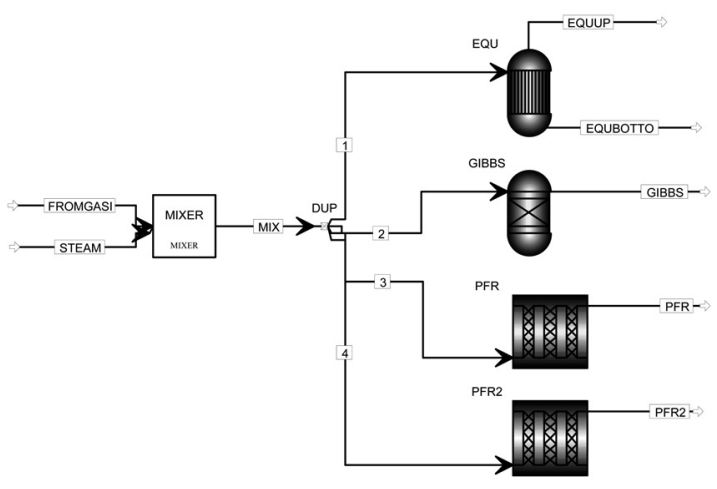

Fig. 7 Configuration of direct water quench process

"ASPEN Plus Model for Entrained Flow Coal Gasifier","13) 의 문헌에 근거하였으며, 체류시간의 경우, 계산은 식 (1)을 사용하여 반영하였다.

$$
t=\int_{0}^{V_{R}} \frac{1}{V} d V_{R}
$$

Plug flow reactor(PFR)에서 체류시간의 계산은 가 스 상의 속력에 의존하게 되는데, 고체(solid)의 경우 에는 고체상의 속력과 연관되도록 보정이 필요하다. 이를 위하여 크게 세 가지 부분을 고려하여 ASPEN plus 내 계산블록(calculation block)을 사용하였다. Stokes' 식을 사용하여 시스템에서의 고체 입자의 속력을 계 산하였고, 가스화기의 길이와 체류시간사이의 관계 는 Newton's 방법을 이용하여 계산하였고 그 계산값 을 plug flow reactor(PFR)에 반영하였다 ${ }^{13)}$.

\subsection{Quenching 시스템}

가스화기 내에서 이루어지는 water quench 시, 수 성가스화 전환 반응이 일부 일어나는 것으로 알려져 있다. 본 연구에서는 가스화기 내에서 water quench 를 통해 합성가스의 조성이 어떻게 변화 되고, 얼마 만큼의 열 손실이 발생하게 되는지 radiant syngas cooler사용 시와 비교하여 살펴보고자 한다. 가스화 기 내의 고온 고압의 환경을 모사하기 위하여 평형 (equilibrium) 반응기, 깁스(gibbs) 반응기, 관형 반응
기를 이용하여 각각 모사하여 보았다. 관형 반응기의 경우 문헌값 ${ }^{11)}$ 의 속도식을 반영하여 모사를 수행하 였다.

공정도는 Fig. 7에 나타나 있다.

이 중 관형 반응기는 최종적으로 열정산을 위하여 등온과 단열 공정을 이용한 두 가지 종류로 모사를 수행하여 비교하였다. 이 때 반응기의 크기는 직경 $1.5 \mathrm{~m}$, 높이 $0.3 \mathrm{~m}$ 로 적용하였고 이를 바탕으로 체류 시간은 계산되었다.

\section{3 수성가스화 전환반응(WGS Reaction)}

수성가스화전환반응의 경우에 이미 많은 연구에 서 다양한 촉매들을 대상으로 평가되었고, 대상 촉매 를 사용하는 경우에 대한 속도식들이 알려져있다. 다 양한 경로를 통해 속도결정단계를 예측하고 있다. 본 연구에서, 수성가스화 전환 반응을 모사하고 최적화 된 운전 조건을 확인하기 위하여 Choi와 Stenger에 의해 발표된 내용을 사용하였다 ${ }^{12}$. 밀도 $\left(\rho_{\mathrm{cat}}\right)$ 가 150 $l b / f t^{3}$ 인 $\mathrm{Cu} / \mathrm{ZnO} / \mathrm{Al}_{2} \mathrm{O}_{3}$ 로 구성된 촉매를 사용하였 고 반응에 관한 정반응과 역반응의 반응 속도식은 다음 식 (2), (3)과 같다.

$$
\begin{aligned}
& R_{F}=k_{f} e^{-E_{f} / R T} P_{C O} P_{H_{2} O} \\
& R_{R}=k_{R} e^{-E_{R} / R T} P_{C O_{2}} P_{H_{2}}
\end{aligned}
$$

여기에서, $R_{F}$ 는 정반응, $R_{R}$ 는 역반응을 의미하며 단위는 $\mathrm{kmol} / \mathrm{sec} \cdot \mathrm{m}^{3}$ 이다. $k_{F}$ 와 $k_{R}$ 는 정반응과 역 반응의 속도상수로 $2.074 \times 10^{-7} \mathrm{kmol} / \mathrm{sec} \cdot \mathrm{m}^{3} \cdot \mathrm{Pa}^{2}$ 과 $1.575 \times 10^{-5} \mathrm{kmol} / \mathrm{sec} \cdot \mathrm{m}^{3} \cdot P a^{2}$ 이다. $E_{F}$ 와 $E_{R}$ 은 정반 응과 역반응의 활성화 에너지로 $47,400 \mathrm{~kJ} / \mathrm{kmol}$ 과 $85,460 \mathrm{~kJ} / \mathrm{kmol}$ 이다. $P_{j}$ 의 경우 각 성분(j)의 부분압 력이다 ${ }^{12)}$.

공정모사를 위해 상기 조건을 반영하여 공정시뮬 레이터인 ASPEN PLUS를 사용하여 모사하였다 ${ }^{13)}$. 연산의 기초가 되는 열역학 방정식은 peng-robinson 


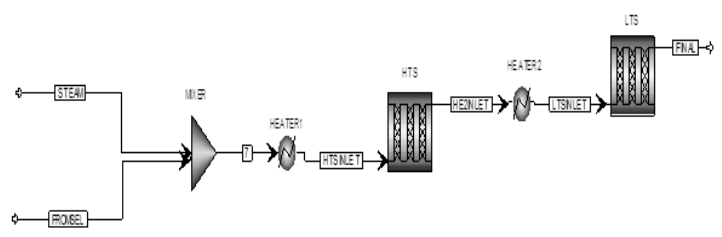

Fig. 8 Configuration of WGS reaction process

방법을 사용하였고 냉각된 합성가스에 스팀(steam)을 추가로 공급하였다. Water quench와 radiant syngas cooler를 사용한 경우에 합성가스 내 수분의 함량이 다르기 때문에, 수성가스화 전환 반응 시 추가되는 스팀의 양이 다르게 된다. 수성가스화 전환반응을 통 해 생성되는 열을 열교환기를 이용하여 온도제어를 수행하였고 각 단위기기별 압력강하는 0.34atm(5 psi) 를 반영하였다. 공정도는 Fig. 8에 나타나 있다.

\section{4. 공정 모사 결과}

Table 1에 나와 있는 대상탄에 대하여 가스화기 모사결과를 NETL에서 제공하는 자료와 비교하여 그 결과는 Table 2에 나타나있다.

Table 2 Simulation results after gasification

\begin{tabular}{|c|c|c|}
\hline Item & NETL (mol\%) & Lee's model ${ }^{1)}(\mathrm{mol} \%)$ \\
\hline $\mathrm{Ar}$ & 1.04 & 0.00 \\
\hline $\mathrm{CH}_{4}$ & 0.00 & 0.12 \\
\hline $\mathrm{CO}$ & 60.16 & 58.79 \\
\hline $\mathrm{CO}_{2}$ & 3.18 & 2.94 \\
\hline COS & 0.05 & 0.00 \\
\hline $\mathrm{H}_{2}$ & 26.16 & 28.82 \\
\hline $\mathrm{H}_{2} \mathrm{O}$ & 2.79 & 2.44 \\
\hline $\mathrm{H}_{2} \mathrm{~S}$ & 0.30 & 0.00 \\
\hline $\mathrm{N}_{2}$ & 6.04 & 6.89 \\
\hline $\mathrm{NH}_{3}$ & 0.29 & 0.00 \\
\hline $\mathrm{O}_{2}$ & 0.00 & 0.00 \\
\hline $\mathrm{SO}_{2}$ & 0.00 & 0.00 \\
\hline Total flow $(\mathrm{kg} / \mathrm{hr})$ & 375,047 & 375,032 \\
\hline Temp $\left({ }^{\circ} \mathrm{C}\right)$ & 1,427 & 1,450 \\
\hline Pressure (atm) & 41.84 & 42 \\
\hline
\end{tabular}

Table 3 Simulation results after water quenching

\begin{tabular}{c|c|c|c|c}
\hline \hline Item & $\begin{array}{c}\text { NETL } \\
(\mathrm{mol} \%)\end{array}$ & $\begin{array}{c}\text { Equil. } \\
(\mathrm{mol} \%)\end{array}$ & $\begin{array}{c}\text { Gibbs. } \\
(\mathrm{mol} \%)\end{array}$ & $\begin{array}{c}\text { PFR } \\
(\mathrm{mol} \%)\end{array}$ \\
\hline $\mathrm{Ar}$ & 0.60 & 0.60 & 0.80 & 0.60 \\
\hline $\mathrm{CH}_{4}$ & 0.00 & 0.00 & 16.64 & 0.00 \\
\hline $\mathrm{CO}$ & 34.70 & 1.37 & 0.00 & 34.54 \\
\hline $\mathrm{CO}_{2}$ & 1.83 & 35.15 & 31.96 & 1.99 \\
\hline $\mathrm{COS}$ & 0.03 & 0.03 & 0.00 & 0.03 \\
\hline $\mathrm{H}_{2}$ & 15.08 & 48.40 & 0.09 & 15.24 \\
\hline $\mathrm{H}_{2} \mathrm{O}$ & 43.86 & 10.54 & 45.44 & 43.70 \\
\hline $\mathrm{H}_{2} \mathrm{~S}$ & 0.17 & 0.17 & 0.27 & 0.17 \\
\hline $\mathrm{N}_{2}$ & 3.48 & 3.48 & 4.79 & 3.48 \\
\hline $\mathrm{NH}_{3}$ & 0.24 & 0.25 & 0.01 & 0.25 \\
\hline $\mathrm{O}_{2}$ & 0.00 & 0.00 & 0.00 & 0.00 \\
\hline $\mathrm{SO}_{2}$ & 0.00 & 0.00 & 0.00 & 0.00 \\
\hline Total flow (kg/hr) & 604,961 & 604,952 & 604,952 & 604,952 \\
\hline Temp ( $\left.{ }^{\circ} \mathrm{C}\right)$ & 230 & 230 & 230 & 230 \\
\hline Pressure (atm) & 38.8 & 38.8 & 38.8 & 38.8 \\
\hline & & & & \\
\hline & & & \\
\hline
\end{tabular}

이러한 결과값을 이용하여 water quench를 모사하 기 위해 평형(equilibrium) 반응기와 깁스(gibbs)반응 기 그리고 관형반응기를 사용한 결과를 NETL 보고 서와 비교하여 보았다. 이러한 경우 평형반응기와 깁 스 반응기의 경우, 주성분인 $\mathrm{CO}, \mathrm{CO}_{2}, \mathrm{H}_{2}, \mathrm{H}_{2} \mathrm{O}$ 의 몰 분율(mole fraction)에 있어서 NETL 보고서와 큰 차 이를 보이고 있다. 그 원인은 평형반응기와 깁스 반 응기를 사용하는 경우, 체류시간이나 반응속도에 대한 개념이 반영되지 않기 때문에 가스화기 내에서 water quench 시 수성가스화 전환 반응이 완결되기 때문이 다. 하지만 관형 반응기의 경우 체류시간과 반응속도 식을 반영하여 모델링을 수행하였기 때문에, 합성가 스 내 물이 포화되고 수성가스화 전환 반응은 거의 발생하지 않는다. Water quench 시 관형 반응기의 시 뮬레이션 결과는 NETL 보고서와 오차가 최고 $0.2 \%$ 이다. 그 결과는 Table 3 에 요약하여 정리하였다.

또한 radiant syngas cooler 사용하는 경우에 있어 결과는 Table 4에 요약하여 정리하였다. 이 경우에는 $\mathrm{NETL}$ 자료 중 Fig. 4 의 공정에 근거하여 모사하였다 ${ }^{2}$. 다음으로, 후단의 수성가스화 전환반응에 대하여 
Table 4 Simulation results after radiant syngas cooler

\begin{tabular}{c|c|c|c|c}
\hline \hline Item & $\begin{array}{c}\text { NETL } \\
(\mathrm{mol} \%)\end{array}$ & $\begin{array}{c}\text { Equil. } \\
(\mathrm{mol} \%)\end{array}$ & $\begin{array}{c}\text { Gibbs. } \\
(\mathrm{mol} \%)\end{array}$ & $\begin{array}{c}\text { PFR } \\
(\mathrm{mol} \%)\end{array}$ \\
\hline $\mathrm{Ar}$ & 1.00 & 1.04 & 1.47 & 1.04 \\
\hline $\mathrm{CH}_{4}$ & 0.00 & 0.00 & 21.02 & 0.00 \\
\hline $\mathrm{CO}$ & 60.10 & 57.39 & 38.78 & 60.10 \\
\hline $\mathrm{CO}_{2}$ & 3.20 & 5.94 & 29.47 & 3.23 \\
\hline $\mathrm{COS}$ & 0.00 & 0.05 & 0.50 & 0.05 \\
\hline $\mathrm{H}_{2}$ & 26.20 & 28.92 & 0.00 & 26.21 \\
\hline $\mathrm{H}_{2} \mathrm{O}$ & 2.70 & 0.02 & 0.00 & 2.74 \\
\hline $\mathrm{H}_{2} \mathrm{~S}$ & 0.03 & 0.30 & 0.00 & 0.30 \\
\hline $\mathrm{N}_{2}$ & 6.00 & 6.04 & 8.76 & 6.04 \\
\hline $\mathrm{NH}_{3}$ & 0.30 & 0.29 & 0.00 & 0.29 \\
\hline $\mathrm{O}_{2}$ & 0.00 & 0.00 & 0.00 & 0.00 \\
\hline $\mathrm{SO}_{2}$ & 0.00 & 0.00 & 0.00 & 0.00 \\
\hline Total flow (kg/hr) & 375,047 & 375,047 & 375,047 & 375,047 \\
\hline Temp ( $\left.{ }^{\circ} \mathrm{C}\right)$ & 230 & 230 & 230 & 230 \\
\hline Pressure (atm) & 38.8 & 38.8 & 38.8 & 38.8 \\
\hline & & & &
\end{tabular}

분석하였다. 수성가스화 전환반응을 위해 투입되는 스팀과 일산화탄소의 비 $\left(\mathrm{H}_{2} \mathrm{O} / \mathrm{CO}\right)$ 의 비율을 $1.44 \sim 1.75$ 까지 변화 시켜 가면서 분석을 수행하여 보았다. 이

Table 5 Simulation results after WGS reaction (Bed Voidage $=0.5)$

\begin{tabular}{c|c|c|c|c|c}
\hline \hline \multirow{2}{*}{ Item } & \multicolumn{5}{|c}{$\mathrm{H}_{2} \mathrm{O} / \mathrm{CO}(\mathrm{mol} \%)$} \\
\cline { 2 - 6 } & NETL & 1.75 & 1.65 & 1.54 & 1.44 \\
\hline $\mathrm{Ar}$ & 0.66 & 0.65 & 0.65 & 0.66 & 0.66 \\
\hline $\mathrm{CH}_{4}$ & 0.00 & 0.00 & 0.00 & 0.00 & 0.00 \\
\hline $\mathrm{CO}$ & 0.97 & 0.32 & 0.42 & 0.57 & 0.80 \\
\hline $\mathrm{CO}_{2}$ & 39.70 & 39.93 & 39.87 & 39.78 & 69.65 \\
\hline $\mathrm{COS}$ & 0.00 & 0.03 & 0.03 & 0.03 & 0.03 \\
\hline $\mathrm{H}_{2}$ & 54.40 & 54.55 & 54.50 & 54.43 & 54.33 \\
\hline $\mathrm{H}_{2} \mathrm{O}$ & 0.17 & 0.21 & 0.21 & 0.21 & 0.21 \\
\hline $\mathrm{H}_{2} \mathrm{~S}$ & 0.22 & 0.19 & 0.19 & 0.19 & 0.19 \\
\hline $\mathrm{N}_{2}$ & 3.87 & 3.84 & 3.85 & 3.85 & 3.86 \\
\hline $\mathrm{NH}_{3}$ & 0.00 & 0.27 & 0.27 & 0.27 & 0.27 \\
\hline $\mathrm{O}_{2}$ & 0.00 & 0.00 & 0.00 & 0.00 & 0.00 \\
\hline $\mathrm{SO}_{2}$ & 0.00 & 0.00 & 0.33 & 0.00 & 0.00 \\
\hline Temp ( $\left.{ }^{\circ} \mathrm{C}\right)$ & 185 & 185 & 185 & 185 & 185 \\
\hline Pressure (atm) & 38.3 & 38.3 & 38.3 & 38.3 & 38.3 \\
\hline Conversion (\%) & 97.49 & 99.16 & 98.90 & 98.51 & 95.41 \\
\hline & & & & &
\end{tabular}

Table 6 Comparison of gasification plant cost

\begin{tabular}{c|c|c}
\hline \hline & Shell & Siemens \\
\hline $\begin{array}{c}\text { Gasification Plant Cost } \\
(\$ / \mathrm{kW})\end{array}$ & 630 & 465 \\
$(25.1 \%)$ & $(17.8 \%)$ \\
\hline
\end{tabular}

때 반응기내 촉매층의 공극율은 0.5 를 기준으로 하였 다. NETL 자료의 경우에는 전환율이 $97.5 \%$ 이고 $^{2)}$, 모사결과 $99 \%$ 이상 까지도 전환이 가능할 것으로 예 상되었다. 그 결과는 아래 Table 5과 같다.

본 결과를 통해 살펴보면, 높은 전환율을 위해서 는 $\mathrm{H}_{2} \mathrm{O} / \mathrm{CO}$ 의 비율을 1.75 수준까지 높이는 것이 필 요하다. 하지만 최종 제품에 따라 경제성을 고려를 했을 경우 1.54 수준까지 유지해도 $98.51 \%$ 의 전환율 을 얻을 수 있음을 알 수 있다.

이러한 모델링 결과를 활용하여 $\mathrm{CCS}$ 가 연계된 IGCC 공정에 있어서 water quench 방법과 radiant syngas cooler가 사용되는 경우에 있어 어떠한 방식 이 유리한지에 대한 분석이 필요하다.

NETL 보고서에 따르면 shell과 siemens 가스화기 의 건설 비용이 Table 6 과 같달.

합성가스냉각기의 초기 건설비용이 water quench 방식보다 고가라는 것은 당연한 사실이며 이로 인하 여 shell 가스화기의 건설비용이 더 고가이다. 하지 만, water quench 방식의 경우 열손실이 radiant syngas cooler를 사용할 때 보다 크게 되고, 반대로 radiant syngas cooler를 사용하는 경우 초기 투자비는 많이 소요되지만, 열회수 관점에서 이득이 된다.

이러한 경우에 가스화플랜트의 수명을 고려한 상태 에서 CAPEX(capital expenditures)와 OPEX(operating expenditures)의 분석을 통해 비교하는 것이 필요하 다. 초기 투자비 대비하여 radiant syngas cooler의 사 용에 따른 효율증가를 금액으로 환산하였을 때, 초기 투자비를 얼마 동안의 기간 안에 회수가 가능한 지 알아보고, 그 회수 가능 기간을 가스화기 수명과 비 교하였을 때 경제성을 예측할 수 있을 것이다. 현재 공개된 자료들의 부족으로 정확한 분석을 수행하는 것은 어렵다. 예를 들면, radiant syngas cooler를 사용 하는 경우에 후단에 사용이 필수적인 필터의 종류와 
가격, 그리고 교체 주기 등에 대한 정보가 필요하며, water quench시에는 폐수 처리에 소요되는 비용 정보 가 필요하다. 하지만 본 시뮬레이션을 통해 손실되는 열량과 회수 가능한 총열량을 계산하고 나머지 부분 에 대한 가정을 통해, 경제성에 대한 고려가 가능하다. 본 시뮬레이션을 통해 각 흐름의 엔탈피(enthalpy) 값 을 통하여 관형반응기의 단열 그리고 일정온도를 유 지하도록 모사된 모델링을 바탕으로, 손실되는 열량 과 회수 가능한 총열량을 비교하는 것이 가능하다. Water quench 시에는 스팀이 합성가스 흐름에 포화 되는 과정을 통해 일부의 현열이 사용되고 나머지는 손실이 된다. $500 \mathrm{MW}$ 급 siemens 가스화기를 기준으 로 했을 때 $50 \mathrm{MW}$ 가량의 열 손실이 발생한다. 또한 합성가스 냉각기가 설치된 경우 $140 \mathrm{MW}$ 의 정도의 열을 회수할 수 있다. 하지만 후단의 수성가스화 전 환반응을 위해 $\mathrm{H}_{2} \mathrm{O} / \mathrm{CO}$ 를 1.54 로 유지하기 위해 투 입되어야 하는 양이 radiant syngas cooler 사용하는 경우 많게 된다. 해당 대상탄, 그리고 합성가스 냉각 기의 효율, 후단의 수성가스화 전환 반응에 걸쳐 전 반적으로 비교 분석 수행이 필요하다.

\section{5. 결 론}

본 연구를 통하여, 석탄 투입부터 수성가스화 전환 반응까지 모사를 수행하여 결과를 얻을 수 있었다. 모 사의 방법론적인 관점에서 수성가스화 전환 반응의 경 우 관형 반응기를 통해 모사가 가능함을 알 수 있었다. 또한 수성가스화 전환 반응에서 $\mathrm{Cu} / \mathrm{ZnO} / \mathrm{Al}_{2} \mathrm{O}_{3}$ 로 구성 된 촉매를 사용하는 경우에 대하여 스팀의 주입량에 대한 민감도 분석(sensitivity analysis)를 수행하였다.

수성가스화 전환 반응이 필요한 IGCC 공정 및 기 타 다른 공정에 대하여 건설비와 운영비를 동시에 고려하여 적정한 설계 조건을 찾는데 본 연구가 유 용하게 활용될 수 있을 것이다.

\section{참 고 문 헌}

1. Joongwon Lee, Miyeong Kim, Junhwa Chi, Simoom
Kim, Seik Park, “A Study of Coal Gasification Process Modeling", Trans. of the Korean Hydrogen and New Energy Society, Vol. 21, No. 5, 2010, p. 425.

2. James B. Black; "Cost and Performance Baseline for Fossil Energy Plants, Volume 3a : Low Rank Coal to Electricity : IGCC Case", 2011.

3. Higman C., Van der Burgt M., "Gasification", 2nd, 2003.

4. David A. Bell, Brian F. Towler and MaoHong Fan, "Coal Gasification and its Application", 1st, 2011.

5. http://www.netl.doe.gov/technologies/coalpower/ gasification/gasifipedia/4-gasifiers/4-1-2-3_she 1l.html

6. Anton Haberzettl, "Siemens Gasification Technology, General Introduction", 2011.

7. Patrick J. Robinson and William L. Luyben, "Integrated Gasification Combined Cycle Dynamic Model : H2S Absorption/ Stripping/ Water-Gas Shift Reactors, and CO2 Absorption/ Stripping”, Ind. Eng. Chem. Res., 49, 2010, p. 4766.

8. Christian Kunze, Hartmut Spliethoff, "Modelling, comparison and operation experiences of entrained flow gasifer", Energy Conversion and management, 52, 2011, p. 2135.

9. F.Kiso, M. Matsuo, "A Simulation study on the enhancement of the shift reaction by water injection into a gasifier", Energy, 36, 2011, p. 4032.

10. Chen C., Horio M., Kojima T., "Numerical simulation of entrained flow coal gasifier Part I.: modeling of coal gasification in an entrained flow gasifier.", Chemical Engineering Science, 55, 2000, p. 3861.

11. Colomba Di Blasi, "Dynamic behaviour of stratified downdraft gasifier", Chemical Engineering Science, 55, 2000, p. 2931.

12. Choi. Y., Stenger. H. G., "Water-gas Shift reaction kinetics and reactor modeling for fuel cell garde hydrogen", J. Power Sources, 124, 2003, p. 432.

13. ASPEN Technology, Inc. "ASPEN Plus Model for Entrained Flow Coal Gasifier” V7.2, http://support. aspentech.com 